Original Article

\title{
ULTRASOUND DIFFERENTIATION OF BENIGN AND MALIGNANT CERVICAL LYMPH NODES
}

\author{
Md. Mizanur Rahman' ${ }^{1}$ ASQM Sadeque ${ }^{2}$, Eliza Omar $^{3}$ and Sonjoy Kumar Bhakta ${ }^{4}$ \\ ${ }^{1}$ Department of Radiology and Imaging, Dhaka Medical College, Dhaka, ${ }^{2}$ Department of Radiology and \\ Imaging, BIRDEM, Dhaka, ${ }^{3}$ Department of Pharmacology and Therapeutics, Shaheed Suhrawardy Medical \\ College, Dhaka, ${ }^{4}$ Department of Radiology and Imaging, Sadar Hospital, Narsingdi
}

\begin{abstract}
This study was conducted to see whether the size (measured by maximal short axis diameter), shape (expressed in terms of ratio dividing long axis diameter of the node by short axis diameter or $\mathrm{L} / \mathrm{S}$ ratio), marginal clarity (regular or irregular margin), internal echo-pattern (homogeneous hypoechoic or heterogeneous) and hilar echogenicity (presence or absence of echo-genicity in hilum) are good criteria for differentiating benign from malignant cervical lymph nodes using high frequency (high resolution) ultrasound probe. The study was carried out from January 1998 to December 1998, among patients with enlarged cervical lymph nodes who were scanned with a high frequency (5.0 $\mathrm{MHz}$ ) curvilinear probe. Chi-Square test was done to see the statistical correlation between two groups of nodes. A p value of $<0.05$ was taken as significant. Out of 65 nodes studied, 26 (100\%) enlarged cervical nodes with short axis diameter more than $1 \mathrm{~cm}$ were all malignant. In contrast 31 (79.5\%) of 39 enlarged nodes with short axis diameter less than $1 \mathrm{~cm}$ were benign and rest were malignant $(\mathrm{p}<0.001)$. Of 34 enlarged nodes with $\mathrm{L} / \mathrm{S}$ ratio $<2,30(88.2 \%)$ nodes were found malignant and 4 (11.8\%) were benign. Among the rest 31 enlarged nodes, 27 (87.1\%) with L/S ratio $\geq 2$ were benign while $4(12.9 \%)$ were malignant $(\mathrm{p}<0.001)$. Among the 39 nodes with regular margin 28 (71.8\%) were found benign, where as among 26 nodes with irregular margin $23(88.5 \%)$ were malignant $(\mathrm{p}<0.001)$. When the internal echopattern was taken in account, 32 nodes had homogeneous hypoechoic echo of which $28(87.5 \%)$ were benign and among 33 nodes with heterogeneous echopattern 30 (90.9\%) were malignant ( $\mathrm{p}<0.001)$. Among the 43 enlarged nodes with presence of hilar echogenicity $31(72.1 \%)$ were found benign and $22(100 \%)$ nodes with no hilar echogenicity were all malignant $(p<0.001)$. Such findings suggest that real time high resolution ultrasound might assist in differentiation of benign and malignant enlarged cervical lymph nodes.
\end{abstract}

Ibrahim Med. Coll. J. 2009; 3(2): 40-44

Indexing words: Ultrasound, cervical lymph nodes, benign, malignant.

\section{Introduction}

Inflammation of the lymph nodes of the neck is and exceedingly common from infections of the oral and nasal cavity, ear, scalp and face. Mann stated that secondary carcinomatous infiltration of the cervical lymph node is only too common. ${ }^{1}$ Palpation of the node is a basic technique for detection of cervical lymph node metastasis with accuracy between $60-87.5 \%{ }^{2-4}$ Different imaging techniques have been employed to improve the result of palpation, among them high resolution ultrasound is credited with the highest sensitivity, being able to detect superficial diseased nodes as small as $2 \mathrm{~mm} .^{5-7}$

FNAC (Fine needle aspiration cytology) has an important role in the diagnosis of diseases of enlarged cervical lymph nodes with good diagnostic yield. Procedure is easy, safe, simple, quick, inexpensive

Address for Correspondence:

Dr. Md. Mizanur Rahman, Assistant Professor, Department of Radiology and Imaging, Dhaka Medical College, Dhaka. Cell no-01711 166744 
and reliable,${ }^{8}$ but biopsy of the cervical lymph node is most important so far as diagnosis is concerned. However, both the procedures are invasive.

On the other hand, ultrasound is noninvasive, inexpensive and an easily available technique for examining cervical lymph nodes. Ultrasound has one particular advantage in that it allows free rotation of the scanning plane and can instantly show the parameters used in this study. Although ultrasound has proved to be a valuable tool for the detection of the enlarged lymph nodes, differentiation between benign and malignant nodal diseases remains a problem. ${ }^{9-12}$

Bruneton et al., Hajek et al. and Sakai et al. ${ }^{13-15}$ suggested nodal size to be a reliable indicator for differentiating benign from malignant nodes. Another group of authors suggested that L/S ratio is a reliable indicator of a metastatic node. ${ }^{9-11,15}$ Toriyabe et al. ${ }^{16}$ described different types of echopattern in lymph nodes. They concluded that homogeneous hypoechoic pattern was seen more in benign enlarged nodes whereas heterogeneous patterns of echo were more common in metastatic nodes. Sanders ${ }^{17}$ claimed that echogenic hilum in a large node is a good indicator that it is benign and is due to fat deposition. Rubaltelli et al. ${ }^{18}$ also concluded that echogenic hilum is a valid criterion for benignity. Some authors differed and opined that echogenic hilum is not specific for benignity or malignancy. ${ }^{10,19}$

So, in this study these five parameters (Size, Shape, Marginal clarity, Internal echopattern and hilar echogenicity) were selected to see whether these could be reliable indicators for differentiation of benign from malignant groups of enlarged cervical lymph nodes.

\section{Materials and Methods}

The study was carried out in the Department of Radiology and Imaging, Bangabandhu Sheikh Mujib Medical University (BSMMU) and Dhaka Medical College Hospital (DMCH) from January 1998 to December 1998. Patients having enlarged cervical lymph nodes were scanned by high frequency $(5.0 \mathrm{MHz})$ curvilinear probe. Lymph node size (measured by maximal short axis diameter), lymph node shape (expressed by dividing the long axis diameter by the short axis diameter or L/S Ratio), marginal clarity, internal echopattern and hilar echogenicity were the criteria that were individually brought into consideration for differentiating benign from malignant nodes (Table 1).
Table-1: Ultrasound criterion used in this study to differentiate benign from malignant.

\begin{tabular}{lcc}
\hline Ultrasound criterion & Benign & Malignant \\
\hline $\begin{array}{l}\text { Size } \\
\text { (Maximal short axis diameter) }\end{array}$ & $<1 \mathrm{~cm}$ & $>1 \mathrm{~cm}$ \\
$\begin{array}{l}\text { Shape } \\
\text { (Expressed by L/S ratio) }\end{array}$ & $\geq 2$ & $<2$ \\
$\begin{array}{l}\text { Margin of the enlarged node } \\
\text { Internal echopattern }\end{array}$ & $\begin{array}{c}\text { Regular } \\
\text { Homogeneous } \\
\text { hypoechoic }\end{array}$ & $\begin{array}{c}\text { Irregular } \\
\text { Heterogeneous }\end{array}$ \\
Hilar Echogenicity & Present & Absent \\
\hline
\end{tabular}

After ultrasound evaluation, specimens were collected by excision biopsy. Gross and histopathological examinations were then done. Data collected from each individual was then analyzed using computer based statistical software. Chi-square test was used and a $\mathrm{p}$ value of $<0.05$ was taken as significant.

\section{Results}

Forty-three patients with solitary or multiple cervical lymphadenopathy were studied. Total number of examined nodes was 65 . Of the 43 patients, age ranged from 11-70 years maximum being between 51-60 years $(44.2 \%) ; 32(74.4 \%)$ were males and $11(25.6 \%)$

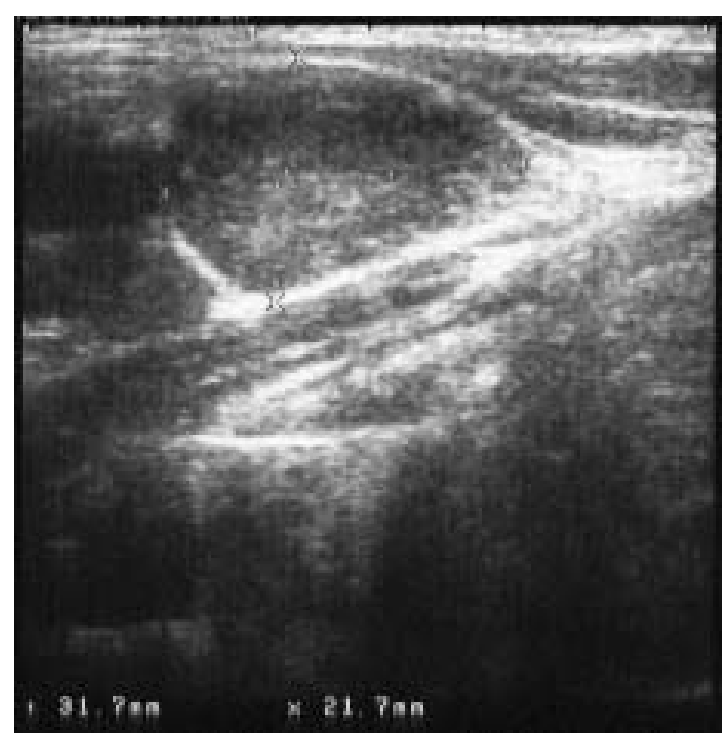

Fig-1. Shows a maximal short axis diameter of $21.7 \mathrm{~mm}$ and a L/S Ratio of 1.46. The node was a metastatic carcinoma. Smooth margin is missing at places. Echo pattern is heterogeneous with no hilar echogenic line. 


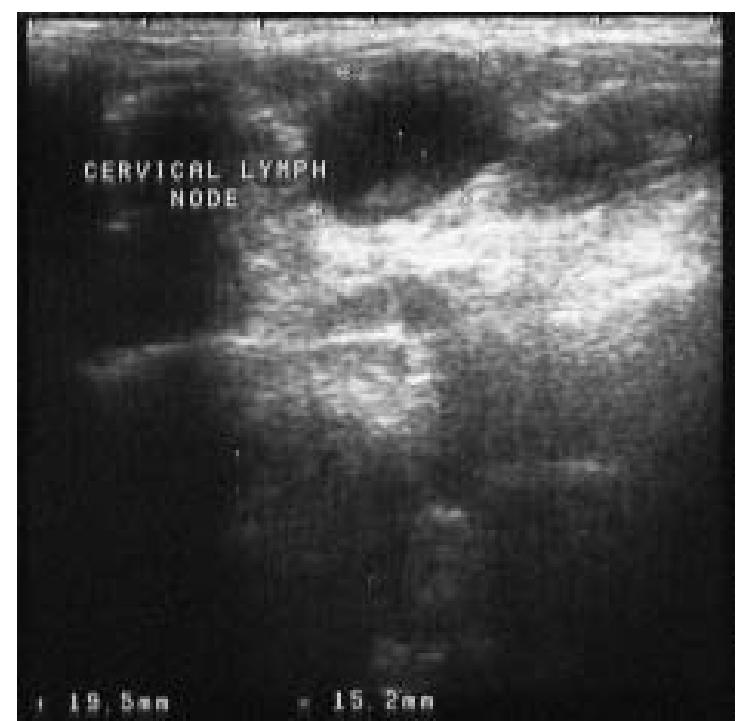

Fig-2. Shows a maximal short axis diameter of $15 \mathrm{~mm}$, a $L / S$ ratio of 1.28 and was proved to be a metastatic enlarged cervical node. Margin in this node was regular with hypoechoic homogeneous echo pattern with absence of hilar echogenicity.

females. Among the commonly involved nodes 21 $(32.3 \%)$ were jugulo-digastric and $19(29.2 \%)$ were from the sub-mandibular group. Of the 65 enlarged nodes $34(52.3 \%)$ were malignant and the rest were benign. Metastatic carcinoma $(31,47.7 \%)$ was commonest in the malignant group and granulomatous lymphadenopathy $(19,29.2 \%)$ in the benign category.

Among the 65 enlarged nodes, 39 had a maximal axial diameter $<1 \mathrm{~cm}$, of which $31(79.5 \%)$ were histopathologically benign and the rest $8(20.5 \%)$ were malignant. $26(100 \%)$ nodes with maximal axial diameter of $>1 \mathrm{~cm}$ were all histo-pathologically malignant and none were benign $\left(\chi^{2}=39.5 ; \mathrm{df}=1.0\right.$; $\mathrm{p}<0.001)$.

Regarding shape, 31 nodes had $\mathrm{L} / \mathrm{S}$ ratio $\geq 2$ of which $27(87.1 \%)$ were histo-pathologically benign and 4 (12.9\%) were malignant. Number of nodes with L/S ratio $<2$ were 34 , of which $30(88.2 \%)$ were histopathologically malignant and $4(11.8 \%)$ were benign $\left(\chi^{2}=36.9 ; \mathrm{df}=1.0 ; \mathrm{p}<0.001\right)$.

Marginal clarity was the third selected parameter. In this group 39 nodes had regular margin, of which 28 (71.8\%) were benign and $11(28.2 \%)$ were malignant. Among 26 nodes with irregular margin, 23 (88.5\%) were malignant and $3(11.5 \%)$ were benign. $\left(\chi^{2}=22.69\right.$; $\mathrm{df}=1.0 ; \mathrm{p}<0.001)$.
Table-1: Results of different parameters used in the study and comparison of findings between benign and malignant enlarged cervical lymph nodes

\begin{tabular}{|c|c|c|c|c|c|}
\hline \multirow{2}{*}{\begin{tabular}{l|} 
Sonographic \\
Parameters used
\end{tabular}} & \multirow{2}{*}{\begin{tabular}{|c|} 
Number \\
Total 65 \\
\end{tabular}} & \multicolumn{2}{|c|}{ Benign } & \multicolumn{2}{|c|}{ Malignant } \\
\hline & & No & $\%$ & no & $\%$ \\
\hline \multicolumn{6}{|c|}{ Maximal short axis diameter } \\
\hline$<1 \mathrm{~cm}$ & $\mathrm{n}=39$ & 31 & 79.49 & 08 & 20.51 \\
\hline$>1 \mathrm{~cm}$ & $\mathrm{n}=26$ & 0 & 0 & 26 & 100 \\
\hline \multicolumn{6}{|l|}{ L/S Ratio } \\
\hline$\geq 2$ & $\mathrm{n}=31$ & 27 & 87.10 & 04 & 12.90 \\
\hline$<2$ & $\mathrm{n}=34$ & 04 & 11.76 & 30 & 88.24 \\
\hline \multicolumn{6}{|l|}{ Margin } \\
\hline Regular & $\mathrm{n}=39$ & 28 & 71.79 & 11 & 28.21 \\
\hline Irregular & $\mathrm{n}=26$ & 03 & 11.54 & 23 & 88.46 \\
\hline \multicolumn{6}{|l|}{ Echopattern } \\
\hline \multicolumn{6}{|l|}{ Homogeneous } \\
\hline hypoechoic & $\mathrm{n}=32$ & 28 & 87.50 & 04 & 12.50 \\
\hline Heterogeneous & $\mathrm{n}=33$ & 03 & 9.09 & 30 & 90.91 \\
\hline \multicolumn{6}{|l|}{ Hilar Echogenicity } \\
\hline Echogenic & $\mathrm{n}=43$ & 31 & 72.10 & 12 & 27.90 \\
\hline No echogenicity & $\mathrm{n}=22$ & 0 & 0 & 22 & 100 \\
\hline
\end{tabular}

All the individual parameters showed high statistical significance $(\mathrm{p}<0.001)$.

Of the 32 enlarged nodes with homogeneous hypoechoic echo-pattern, 28 (87.5\%) were benign and 4 (12.5\%) were malignant. 33 nodes showed heterogeneous echopattern of which $30(90.9 \%)$ were malignant and $03(9.1 \%)$ were benign. $\left(\chi^{2}=42.17 ; \mathrm{df}=1.0 ; \mathrm{p}<0.001\right)$.

Finally presence or absence of hilar echogenicity was sonographically evaluated among the 43 enlarged cervical nodes with echogenic hilum. $31(72.1 \%)$ were benign and 12 (27.9\%) were malignant. All the 22 $(100 \%)$ nodes with absence of hilar echogenicity were found to be malignant. $\left(\chi^{2}=30.33 ; \mathrm{df}=1.0 ; \mathrm{p}<0.001\right)$.

\section{Discussion}

There are approximately 800 lymph nodes in the body of which 300 lie in the neck. ${ }^{1}$ In this prospective study, nodal size, shape, marginal clarity, internal echopattern and hilar echo-genicity were the criteria selected to differentiate benign from malignant group of enlarged cervical lymph nodes.

Van den Brekel $^{3}$ emphasized that maximal short axis diameter is the most accurate measurement for predicting tumor positive nodes. Different authors ${ }^{13,16}$ suggested a short axis diameter of more than $10 \mathrm{~mm}$ (71.4\%) to be malignant and none of the benign nodes 
had short axis diameter more than $1 \mathrm{~cm}$. This study showed that $26(100 \%)$ nodes with short axis diameter $>1 \mathrm{~cm}$ was malignant where as $31(79.5 \%)$ of the nodes with short axis diameter $<1 \mathrm{~cm}$ was benign. These findings are similar to the above studies.

As far as the L/S ratio was considered, among the nodes with $\mathrm{L} / \mathrm{S}$ ratio $<2,30(88.2 \%)$ were malignant and $4(11.8 \%)$ were benign. Among the nodes with $\mathrm{L} / \mathrm{S}$ ratio $\geq 2,27(87.10 \%)$ were benign and $04(12.90 \%)$ malignant. Steinkemp et al. ${ }^{20}$ found $90 \%$ of the enlarged nodes to be metastatic with $\mathrm{L} / \mathrm{S}$ ratio $<2$. Vassallo et al. ${ }^{10}$ showed that $86 \%$ of primary nodal malignancies and $85 \%$ of nodal metastasis had L/S ratio $<2$. So, malignant nodes have larger axial diameter thus reducing the $\mathrm{L} / \mathrm{S}$ ratio and the malignant nodes becoming more roundish. This was also found true in this series.

Regarding the marginal clarity, among 39 enlarged nodes with regular margin, 28 (71.8\%) were benign. Among the 26 enlarged nodes with irregular margin, $23(88.5 \%)$ showed features of malignancy. The results are in conformity with the results of Toriyabe et al. ${ }^{16}$ Ishii et al. ${ }^{6}$ reported that metastatic nodes may show clear regular margin, when early meatastasis has taken place and differentiating may be difficult. In this series, 11 enlarged metastatic nodes showed regular margin.

In this study, $28(87.5 \%)$ nodes were benign among 31 enlarged nodes with homogeneous hypoechoic internal echopattern. In contrast 30, (90.9\%) were malignant among 34 enlarged nodes with heterogeneous echopattern. Toriyabe et al. ${ }^{16}$ showed $90.9 \%$ nodes with homogeneous hypoechoic pattern to be benign and $86.7 \%$ with heterogeneous echopattern to be malignant. These findings are also consistent with the findings of the present study.

Last parameter used in this study was presence or absence of echogenic hilum. Vassallo et al. ${ }^{10}$ showed that $58 \%$ of benign enlarged nodes showed central echogenic hilum, 34\% echogenic narrow hilum and $8 \%$ with no echogenicity at all in the hilum. In this study, $31(72.0 \%)$ nodes with echogenic hilum were benign and $22(100 \%)$ with no hilar echogenicity to be malignant. These findings are in harmony with Evans et al. ${ }^{19}$ who argued that linear echogenic hilum should not be regarded as the sole criterion for a node to be benign.

\section{Conclusion}

This study was performed using a 5.0 MHz high frequency probe. Probe with a larger frequency like 7.5 $\mathrm{MHz}$ might have shown the above signs more clearly, particularly the marginal clarity, internal echopattern and presence or absence of echogenic hilum. But this much can be concluded that when all the parameters are evaluated simultaneously, a better interpretation or differentiation between benign and malignant cervical nodes is possible with real time high resolution ultrasound.

\section{References}

1. Mann CV, Russell RCG, Williams NS. Editors, Lymphatics and Lymph nodes and The Neck. In Bailey and Love's short practice of surgery, $22^{\text {nd }}$ edition ELBS with Chapman and Hall, London. 1995; 187-94 and 497-505.

2. Baatenburg de Jong RJ, Rongen RJ, Lameris JS. Metastatic node disease, palpation VS ultrasound examination. Arch Otolaryngol Head Neck Surg 1989; 115: $689-90$.

3. Van den Brekel MWM, Stel HV, Castaijns JA. Lymph node staging in patients with clinically negative neck examination by ultrasound and ultrasound guided aspiration cytology. Am J Surg 1991; 162: 362-6.

4. John DG, Williams SR, Anaes FC. Palpation compared with ultrasound in the assessment of malignant cervical lymph nodes. J Laryngol Otolaryngol 1993; 107: 82123.

5. Marchal G, Oyen R, Verschakelen J, Gelin J, Baert L, Steessens RS. Sonographic appearance of normal lymph nodes. J of Ultrasound Med 1991; 4: 417-19.

6. Ishii J, Amagasa T, Tachibana T. US and CT evaluation of cervical lymph node metastasis from oral cancer. J Cranio-Max-Facial Surg 1991; 19: 123-7.

7. Cole I, Chu J, Kos S. Metastatic carcinoma in the neck: A clinical, computerized tomography scan and ultrasound study. Aust NZ J Surg 1993; 63: 468-74.

8. Gupta AK, Nayar M. Critical appraisal of fine needle aspiration cytology in tuberculous lymphadenitis. Acta Cytol 1992; 36: 391-4.

9. Ishii J, Amagasa T, Tachibana T. Ultrasonic evaluation of cervical lymph node metastasis of squamous cell carcinoma in oral cavity. Bull Tokyo Med Dent Univ 1989; 36: 63-7.

10. Vassallo P. Wernecke K, Ross N, Peter PE. Differentiation of benign from malignant superficial lymphadenopathy: The role of high resolution US. Radiology 1992; 188: 215-20. 
11. Vassallo P. Edel G, Ross N. In vitro high resolution ultrasonography of benign and malignant lymph nodes: A sonographic-pathologic correlation. Invest Radio 1993; 28: 698-705.

12. Eichorn T, Schroeder HG. Ultrasound in metastatic neck diseases. J Oto Rhino Laryngol related special 1993; 55: 256-62.

13. Bruneton JN, Roux P, Caramella E. Ear, nose and throat cancer: Ultrasound diagnosis of metastasis to cervical lymph nodes. Radiology 1984; 12: 771-3.

14. Hajek PC, Salomonowitz E. Lymph nodes of the neck: Evaluation with US. Radiology 1986; 158: 739-42.

15. Sakai F, Kiyono K, Sone S. Ultrasonic evaluation of cervical metastatic lymphadenopathy. J Ultrasound Med 1988; 7: 305-10.

16. Toriyabe Y, Nishimuro T, Kita S, Saito Y, Miyokawa N.
Differentiation between benign and metastatic cervical lymph nodes with ultrasound. Clin Radiol 1997; 52: 927-32.

17. Sanders RC. Neck Mass in clinical sonography, $2^{\text {nd }}$ edition 1984; 369-76.

18. Rubaltelli L,Proto E,Salmaso R,Bortoletto P,Candiani F, Cagol P. Sonography of abnormal lymph nodes in vitro: correlation of sonographic and histologic findings. Am J Roentgenol 1990; 155: 1241-4.

19. Evans RM, Ahuza A, Metreweli C. The linear echogenic hilus in cervical lympadenopathy: a sign of benignity or Malignancy? Clin Radiol 1993; 47: 262-4.

20. Steinkemp HJ, Cornehl M, Hosten N, Pegios N, Vogl T, Felix R. Cervical lymphadenopathy, ratio of long to short axis diameter as a predictor of malignancy. $\mathrm{Br}$ J Radiol 1995; 68: 266-70. 